\title{
A PRÁTICA PEDAGÓGICA DO PROFESSOR DE EDUCAÇÃO FÍSICA E O CORPO DE SEUS ALUNOS: UM ESTUDO COM PROFESSORES UNIVERSITÁRIOS
}

\author{
Sílvia Maria Agatti LÜdorF*
}

\section{RESUMO}

O professor de Educação Física, principalmente o universitário que trabalha na formação dos demais professores de Educação Física, lida, em sua prática pedagógica, com os corpos de seus alunos, teórica ou praticamente. O objetivo deste trabalho é conhecer de que forma tais professores lidam/tratam os corpos de seus alunos. Para isso, uma pesquisa qualitativa foi realizada, através de entrevistas semi-estruturadas aplicadas a quinze professores universitários de determinada universidade pública. Concluiu-se que a prática pedagógica dos professores entrevistados é, preponderantemente, voltada ao corpo-experimento e ao corpo-instrumento, o que denota ainda a grande influência da tradição biologizante e técnica da área.

PALAVRAS-CHAVE: corpo - educação física - formação de professores

\section{INTRODUÇÃO}

\begin{abstract}
lvo de constantes análises oriundas dos mais diversos campos de saber, talvez nunca o corpo tenha sido tão discutido, dissecado, fragmentado, experimentado e cultuado como nos últimos tempos. Mesmo assim, continua misterioso e desafiante, à espreita de novas investigações que possam descortiná-lo.

Pensar o corpo é uma tarefa um tanto complexa, dadas as diversas dimensões que podem ser exploradas. Além de ser o arcabouço físico do ser humano e marcar sua existência material, o corpo compreende as formas de se relacionar, de interagir, de refletir sobre e com o mundo (FERREIRA,1999). Trata-se de uma construção, obviamente concreta, mas moldável, conforme os valores e a cultura provenientes da sociedade onde está inserido.
\end{abstract}

* Professora doutora da Escola de Educação Física e Desportos da Universidade Federal do Rio de Janeiro. 
A sociedade contemporânea tem sido testemunha de um crescente interesse em torno do culto ao corpo ou a cultuação do corpo, com destaque para a exposição do que antes era escondido e, aparentemente, controlado (GOLDENBERG; RAMOS, 2002).

Conforme Pereira (2002), a mídia é uma parceira estratégica para este contexto de alta visibilidade do corpo, característico da sociedade de consumo, por meio da qual divulgam-se formatos e padrões de corpo, bem como maneiras de ser tratado, modificado, produzido e, por que não dizer, reproduzido.

Seja com fins estéticos, esportivos, de saúde, qualidade de vida ou sociabilização, entre outros, o fato é que tem havido um aumento considerável da prática de atividades físicas, evidenciado na proliferação de academias de ginástica ${ }^{1}$ ou na simples observação de pessoas praticantes em locais públicos, como praças, parques e praias.

Independente da frente de trabalho, um dos atores mais reconhecidamente envolvidos com as demandas sociocorporais contemporâneas e, obviamente, com a educação corporal, ainda que nas mais diferentes perspectivas, é o professor/profissional ${ }^{2}$ de Educação Física. Reside aí, a importância de se pesquisar e conhecer como esta interação vem ocorrendo.

$\mathrm{Na}$ perspectiva de desvelamento de uma das facetas do corpo trabalhadas no contexto da Educação Física, este estudo ${ }^{3}$ se destina a analisar um recorte da realidade referente à prática pedagógica de professores universitários de Educação Física atuantes em determinado curso de Licenciatura em Educação Física. Especificamente, o objetivo deste estudo é pesquisar e analisar de que forma tais professores lidam, em suas práticas pedagógicas, com os corpos de seus alunos.

Como estes corpos são vistos e trabalhados? Qual é a natureza da intervenção pedagógica? É reconhecido que os cursos de graduação em Educação Física possuem características peculiares, com aulas teóricas e práticas, mas, quais aspectos vêm sendo privilegiados quando se trata do corpo dos alunos?

Conhecer o que ocorre no contexto da formação de professores de Educação Física é objeto de interesse uma vez que tais profissionais assumem formalmente o papel de formadores (ou reprodutores) de opinião. Ao conhecer de que maneira tal intervenção ocorre, talvez seja possível ter mais subsídios para compreender e analisar a própria prática do professor de Educação Física em um âmbito mais geral. Além disso, espera-se obter elementos para discutir a natureza desta intervenção 
que, embora pedagógica, pode, eventualmente, comportar diferentes conotações merecedoras de elucidação.

Para buscar respostas às perguntas formuladas anteriormente e alcançar os objetivos propostos, foi realizada uma pesquisa de cunho qualitativo em um curso de graduação de Educação Física de determinada instituição pública do Estado do Rio de Janeiro. Participaram quinze professores (correspondente a $20 \%$ do corpo docente), selecionados a partir de critérios como idade, sexo e disciplina que ministravam, a saber: disciplinas relacionadas à Escola, à Academia, ao Esporte e ao Corpo. A esses sujeitos foram aplicadas entrevistas semi-estruturadas e a análise das respostas foi baseada na incidência de categorias que emergiram dos discursos.

Para iluminar a compreensão dos dados empíricos, será utilizado referencial teórico pautado por alguns expoentes da Sociologia do Corpo, ${ }^{4}$ bem como por autores da própria Educação Física. A seguir, serão apresentados e discutidos os dados a respeito dos principais aspectos relacionados à prática pedagógica dos professores e ao corpo de seus alunos, primeiramente em um âmbito geral e, posteriormente, em análise mais detalhada.

\section{A PRÁTICA PEDAGÓGICA DOS PROFESSORES E O CORPO DOS ALUNOS}

Ao serem indagados sobre de que forma, em suas disciplinas ou prática pedagógica, os professores trabalham com o corpo dos seus alunos, as respostas apontaram para duas tendências, conforme pode ser visualizado no quadro 1.

QUADRO 1 - As práticas pedagógicas e o corpo

\begin{tabular}{|l|l|l|}
\hline & $\begin{array}{l}\text { Corpo-instrumento/ corpo performance } \\
\text { Aspectos }\end{array}$ & 5 \\
objetivos & Repetição de movimentos (técnica); \\
ou & $\begin{array}{l}\text { Instrumentalização do aluno para traçar objetivos, acom- } \\
\text { panhar e avaliar; }\end{array}$ & \\
Corpo & - Treinamento de movimentos específicos, tornar o corpo \\
& hábil; \\
& - Instrumento para a prática do desporto; \\
& - Instrumento para adquirir saúde. & \\
\hline
\end{tabular}


Cont. ...

\begin{tabular}{|l|l|l|}
\hline & $\begin{array}{l}\text { Corpo-experimento } \\
\text { Experimentação e vivência prática de aspectos teóricos, } \\
\text { essencialmente técnicos, para futura aplicação. }\end{array}$ & 3 \\
\hline & \multicolumn{1}{|c|}{ Total parcial } & $\mathbf{8}$ \\
\hline $\begin{array}{l}\text { Aspectos } \\
\text { subjetivos } \\
\text { ou } \\
\text { Corpo } \\
\text { abstrato }\end{array}$ & $\begin{array}{l}\text { Corpo subjetivo } \\
\text { Descobertas, sensações, revelações no/do próprio corpo } \\
\text { Reflexão sobre as práticas }\end{array}$ & 5 \\
\hline Outros & $\begin{array}{l}\text { - Corpo como um todo, físico, psíquico e social } \\
\text { Fundamentação teórico/prática da ginástica para aplica- } \\
\text { ção no mercado de trabalho }\end{array}$ & 2 \\
\hline & \multicolumn{1}{|c|}{ Total geral } & $\mathbf{1 5}$ \\
\hline
\end{tabular}

De modo geral, a primeira tendência que emergiu do discurso dos professores está relacionada a aspectos objetivos do corpo e a segunda, a aspectos subjetivos. Em relação aos aspectos objetivos, observa-se que o corpo-instrumento ou corpo performance, e o corpo-experimento surgiram como categorias relevantes, sendo constatados em oito entrevistados $(53,33 \%)$. Destes, cinco constituem o grupo Esporte, ${ }^{5}$ o que significa que a totalidade dos representantes deste grupo detém uma visão semelhante de corpo, ou ainda, de trabalhar este corpo. Os outros três são representantes dos demais grupos: Escola, Academia e Corpo.

O corpo subjetivo, aquele que abarcaria aspectos como criatividade, descobertas e sensações, foi mencionado por cinco professores $(33,33 \%)$, dos quais, três são representantes do grupo Corpo e dois, do grupo Escola.

Outras formas de tratar o corpo dos alunos, quais sejam: como um todo, ou de modo a prepará-lo para o mercado de trabalho, foram mencionadas por dois professores, ambos, coincidentemente, pertencentes ao grupo Academia.

Para compreender de modo mais detalhado o que essas tendências significam, elas serão analisadas em pormenores em dois sub-itens, apresentados a seguir. 


\section{1) Corpo-instrumento e corpo-experimento: duas faces da mesma moeda?}

Foram incluídas as categorias de corpo-instrumento e de corpoexperimento sob a rubrica de aspectos objetivos ou concretos do corpo, pois, como é possível notar, são facetas que envolvem aspectos físicos, motores, portanto, práticos e, até certo ponto, objetivos e concretos.

O corpo-instrumento, que serve para aprender determinada técnica ou ser um instrumento para a prática desportiva, foi privilegiado nas falas de professores do grupo Esporte e poderia ser chamado também de corpo performance, aquele que é avaliado potencialmente pelo que consegue produzir. Alguns dos entrevistados desse grupo demonstraram estranheza quanto à pergunta formulada:

- Em relação ao corpo? Fica estranho falar em relação ao corpo. [...] a gente não tem muito a visão de trabalhar o corpo, só fazer a parte específica, direcionada ao esporte, a questão da condição física, de força, de velocidade, não uma coisa estética, o corpo é visto como instrumento para a prática do esporte: evitar lesões do trabalho que deve ser feito, trabalho específico do desporto (P14, p. 4).

- Em relação ao corpo do aluno? Eu não me relaciono...[...] eu não enfatizo muito em relação ao corpo dele não. Em nenhum momento. Eu enfatizo em relação à técnica, à prática ligada ao esporte. Ao corpo do aluno!? Nem falo! (P15, p. 2).

Ao que parece, a priori, o aluno é visto como ente dissociado de seu corpo, como se o ser humano e seu corpo fossem dimensões antagônicas. $\mathrm{Na}$ verdade, essas respostas remetem a um questionamento anterior: qual seria a concepção de corpo desses professores? É possível inferir que está longe de ser aquela pautada pela Sociologia do Corpo, em que "emissor ou receptor, o corpo produz continuamente o significado, insere ativamente o homem ao interior de um dado espaço social e cultural." (LE BRETON, 2000, p. 4).

O corpo, para esse grupo de professores, possui a conotação de meio para se atingir determinado fim, isto é, o rendimento, ainda que não se trate do rendimento na perspectiva do desporto de alto nível. $\mathrm{O}$ ensino da técnica é o objetivo central, o que poderia ser considerado tendência reducionista da própria Educação Física. 
A valorização de um corpo técnico ou executor de tarefas não é exatamente uma novidade em relação ao contexto da Educação Física. Trata-se de assunto amplamente debatido nas décadas de 1980 e 1990, reconhecidamente período de embates conceituais na área.

Tal valorização poderia ser interpretada como a cristalização da tendência da biologização, apontada por Soares (1990) há uma década e meia, quando a Educação Física seria restrita à educação do físico e do corpo sob a ótica biológica. Segundo a autora, as práticas corporais, como o desporto, constituem-se fenômeno cultural e historicamente construído, mas, ao se privilegiar, por exemplo, o ensino das técnicas, o corpo estaria abstraído de sua realidade material concreta. Para Daolio (1999, p. 94), "toda técnica é cultural, porque fruto de aprendizagem específica de uma determinada sociedade, num determinado momento histórico".

Nesta perspectiva de trabalho com o corpo, o enfoque tradicional não se coaduna com os princípios de uma pedagogia crítica, que não prescinde da técnica, mas propõe o "ensino de destrezas motoras esportivas dotadas de novos sentidos, subordinadas a novos objetivos/fins, a serem construídos com um novo sentido para o próprio esporte" (BRACHT, 2000, p. 17).

O corpo-experimento foi, a propósito, categoria criada para se referir àquele corpo que experimenta diferentes práticas, mas não na perspectiva de descobertas ou de novas sensações corporais, ou seja, aspectos subjetivos. Trata-se, sim, de experimentação à moda positivista, de causa-efeito, visando vivenciar na prática determinados aspectos teóricos julgados importantes pelos professores para que os graduandos experimentem e, posteriormente, possam repassar ou trabalhar com seus futuros alunos, como pode ser elucidado a partir de alguns fragmentos.

- Utilizo muito a atividade prática [...] utilizo o corpo do aluno para que ele possa experimentar, vivenciar as teorias que a gente está discutindo. [...]a utilização do corpo era muito para ele poder vivenciar aquelas atividades, para ele poder perceber através do seu corpo como aquilo afetaria, para mais adiante ele poder também aplicar, tendo uma noção de como aquela atividade afeta o organismo dele (P7, p. 9).

- Eles vão experimentar na prática o que eles aprenderam na teoria ou com a prática mesmo, então, esse elo é importantíssimo na formação deles [...] você tem que passar a idéia, demonstrar aquilo que você pre- 
tende, o gesto esportivo, ele executar e você faz a correção imediata, eu acho essa seqüência fundamental, fantástico, porque propicia você ter condição no ato ali, de fazer a correção do erro porque é muito mais fácil você pegar uma criança que não sabe absolutamente nada e você ensinar, a fase gestual correta, bem próximo do que se chamaria de ideal, né? (P4, p. 10).

Como é possível observar, o discurso biologizante é agora novamente reproduzido, na perspectiva de perceber "fisicamente" as sensações fisiológicas decorrentes da prática de exercícios. A reprodução de um modelo, ou antes, de uma técnica perfeita, é fundamental para que se alcance o rendimento desejado. Estas práticas poderiam ser analisadas como coerentes aos pressupostos da tendência pedagógica de inspiração tecnicista, sobre cujo ponto de vista Resende (1994) entende que o professor acaba assumindo as características de treinador e, os alunos, de atleta.

O corpo-instrumento e o corpo-experimento poderiam ser exemplos dos corpos dóceis, propostos por Foucault (2000), uma vez que são utilizados, transformados e aperfeiçoados, estando sujeitos às técnicas de disciplinamento. Ao que parece, há diversas características dessas técnicas, por exemplo, as relacionadas à organização das gêneses (e outras), citadas pelo referido autor, que poderiam fundamentar teoricamente a compreensão das categorias emergidas do discurso dos professores.

Uma maneira de compreender estas categorias talvez seja utilizando a noção de corpo acessório, proposta por Le Breton (1999), a partir da qual se poderia dizer que o corpo, seja instrumento ou experimento, tem sido tratado como acessório de uma presença físico-corpórea dos alunos; ou ainda, como um acessório para a prática, tanto de técnicas, quanto de sensações.

\section{2) O corpo subjetivo: ampliação de possibilidades corporais}

O corpo subjetivo ou abstrato surgiu, compreensivelmente, na fala de três dos quatro professores de disciplinas ligadas ao Corpo. Neste caso, também, poderia ser utilizada a categoria corpo-experimento, mas o sentido seria diferente daquele apresentado anteriormente. A experimentação ou prática, é vista aqui na perspectiva de vivência 
em busca de descobrir aspectos interiores, que, talvez, até o momento, fossem imperceptíveis. Ou ainda, seria uma forma de criação e experimentação de movimentos diversos e pouco usuais, que poderiam levar o aluno a ampliar sua visão de corpo ou suas possibilidades corporais. O sentido dessa prática está explicitado nos seguintes trechos:

- É uma disciplina teórica e prática [...] enfatizo muito essa questão da prática, porque a teoria, acho que ela é importante, mas eu acho que elas se complementam [...] todos os exercícios nós procuramos buscar na prática, ela traz essa questão de introspecção assim, de perceber essas coisas mais sutis nesse corpo, essa relação do corpo consigo mesmo. [...] a gente fala em osso, a gente fala em partes, em articulações, no corpo anatômico o tempo inteiro. Um corpo anatômico sim, mas que vai além desse contorno, [...] Esse corpo é representacional, ele tem um universo simbólico, ele tem uma relação de conteúdo, de expressão, de forma e conteúdo, então a gente sempre tem esse jogo nas aulas (P10, p. 9).

- é uma disciplina assim, aberta, é uma questão de estudo do movimento, ela não se fecha a nada especificamente. [...] o que a gente faz aqui é abrir o leque de opções. [...] a gente dá umas aulas para eles desenvolverem a questão da prática da combinação dos movimentos, para eles criarem movimentos (P9, p. 11-13).

Observa-se nestes trechos, uma concepção de corpo diferente daquela abordada primeiramente. O sujeito não só pertence ao seu corpo, como é indissociável do mesmo. O professor concebe o corpo em uma dimensão sociocultural, além de considerar aspectos subjetivos como o "perceber-se corpo" e o "ser corpo", que remete, possivelmente, a Merleau-Ponty, um dos referenciais teóricos básicos utilizados por esses professores. $^{6}$

Para estes docentes, o corpo é considerado texto da cultura, como bem diz Campelo (1996, p. 77): “Quando os homens se comunicam, lançam mão de todo um repertório: usam o corpo todo e todos os textos nele latentes ou manifestos participam de cada comunicação. Essas comunicações são textos do corpo: gestos".

A categoria de corpo subjetivo abarca as seguintes subcategorias: descobertas, sensações, revelações, exploração e criação de movimentos, além de reflexão. Essas parecem se coadunar com o corpo comunicativo, um dos tipos de corpo propostos por Arthur Frank (1999). 
Para o autor, o corpo comunicativo é uma práxis, mais do que uma realidade. Sua qualidade essencial reside no fato de se tratar de um corpo em processo de se criar por si próprio, através, por exemplo, de práticas corporais que permitam experimentar várias possibilidades de prazer e de expressão. Frank (1999) argumenta que a dança poderia proporcionar elementos para a emergência do corpo comunicativo.

Observam-se indícios, como as diferentes práticas relatadas pelos professores do grupo Corpo, de haver um movimento em busca de uma práxis que poderia ser associada a este corpo comunicativo. Tal movimento poderia ser ilustrado a partir da menção, pelos professores, de práticas corporais, não necessariamente a dança, que possibilitam exercitar além dos músculos, outras dimensões como a sensório-motora, a consciência corporal, a criação e a reflexão, ao que indica a revisão de literatura, ainda pouco significativas na Educação Física.

A reflexão sobre as vivências ou conteúdos propostos em aula, foi citada como aspecto essencial das práticas pedagógicas em torno do corpo subjetivo, sendo normalmente realizada após o desenrolar da parte prática. É o que se pode concluir dos trechos seguintes.

- Sempre a gente termina com uma reflexão sobre aquilo, ali que foi vivido, o que se percebeu, diferenças e semelhanças, o que eu senti quando eu fazia isso, o que foi bom, aonde eu gostei e aonde eu não gostei, sempre ele está se perguntando sobre esse corpo, ele está refletindo sobre a ação dele sobre cada movimento que ele faz o tempo inteiro, não precisa ser verbalmente, brincando (P10, p. 9).

- Qual a importância do corpo? O que é esse corpo? Para que estou aqui jogando, fazendo uma atividade e uma brincadeira? Nessa brincadeira onde estou envolvida com todos os outros meus colegas, porque é importante estar envolvido com os outros colegas? [...] respeitar esse corpo, conhecer melhor esse corpo, saber o que ele é capaz e o que ele está me ajudando no eu ser eu (P6, p. 8).

Vislumbra-se, a partir dessa interpretação, possíveis formas de lidar/tratar o corpo, que fogem ao convencional relacionado à Educação Física. Talvez aqui resida uma esperança de contradiscurso, ou alternativas de se trabalhar o corpo, a partir de outras perspectivas, que possam, se não confrontar, ao menos, mostrar direções bastante palpáveis, ao discurso biologizante cotidianamente relevado. 


\section{CONSIDERAÇÕES FINAIS}

$\mathrm{Na}$ análise aqui empreendida, observou-se que a prática pedagógica do professor de Educação Física, em especial a do professor universitário, ainda guarda resquícios da herança biologizante e técnica da Educação Física. Tal fato foi corroborado com a emergência de categorias como as do corpo-instrumento ou corpo performance, e do corpo-experimento. No entanto, foi possível vislumbrar, através das menções ao corpo subjetivo, indícios de que discursos provenientes de referenciais teóricos das ciências humanas e sociais vêm sendo gradativamente incorporados, efetivamente, à área de Educação Física. Tal fato pode indicar que o corpo tem ganhado novas dimensões e possibilidades de atuação e reflexão por parte da comunidade da Educação Física.

Cabe ressaltar que não se prega aqui uma renúncia às características historicamente constituídas, tampouco ao caráter biológico ou técnico da Educação Física. Ao contrário, são consideradas dimensões fundamentais de nossa área, que lida com o esporte, com a atividade física, com práticas corporais variadas, enfim, com o corpo em movimento. Contudo, não devem ser exclusivas, ou ainda, reducionistas, como conceber o corpo descontextualizado cultural e socialmente. Talvez aí resida a importância de se trazer pontos de vista diferentes, como alguns dos que embasam a Sociologia do Corpo e brevemente mencionados nesta oportunidade, de modo a iluminar a compreensão em torno deste, que é a essência de nossa área, o corpo.

Ainda que se trate de um determinado recorte da realidade, é possível vislumbrar que a prática pedagógica do professor de Educação Física necessita ser continuamente discutida e revisitada. A forma de intervenção do professor no corpo de seus alunos forneceu algumas pistas de como a situação se delineia e apontou para eventuais caminhos. Urge, entretanto, que iniciativas como a desta revista, de gerar espaço para discussão do trinômio: Educação Física, corpo e cultura, sejam continuamente fomentadas. Somente assim, a partir dos embates críticos, conseguiremos construir uma Educação Física que trabalhe com corpos, mas, acima de tudo, com sujeitos. 


\title{
THE PEDAGOGIC PRACTICE OF THE PHISICAL EDUCATION TEACHER AND THEIR STUDENTS BODIES: A STUDY WITH UNIVERSITY TEACHERS
}

\begin{abstract}
The teacher of Physical Education, especially those who work in the formation of Physical Education teachers, leads, in their pedagogical practice, with the bodies of their students. The aim of this study is to know the way those teachers work with their student's bodies. A qualitative research was conducted by applying semi-structured interviews in fifteen university teachers. In conclusion, the pedagogic practice emphasizes technical and biological aspects related to the bodies. It shows that the biological paradigm is still strongly present in the Physical Education area.
\end{abstract}

KEY-WORDS: body - physical education - teacher's formation

\section{LA PRACTICA PEDAGOGICA DEL PROFESOR DE EDUCACION FISICA E LE CORPO DE SUS ALUMNOS: UN ESTUDIO CON PROFESORES UNIVERSITARIOS}

\section{RESUMEN}

El profesor de Educación Física, en particular el profesor universitário que trabaja en la formación de profesores de esa misma área, se ocupa, teorica/ o practicamente en su práctica pedagógica con el cuerpo de los mismos alumnos. El objetivo del presente trabalho es conocer como tales profesores resuelven en la práctica ese tipo de relacionamento con sus alumnos. Fué realizada una investigación calitativa por médio de entrevistas semi-estructuradas. Los sujetos fueram 15 profesores universitarios. La conclusión más importante es que la práctica pedagógica de los entrevistados es, preponderantemente dirigida al corpo-experimento e al corpo-instrumento donde se percibe la grande influência de las tradiciónes biologizante e técnica en la Educación Física.

PALABRAS-CLAVE: cuerpo - educación física - formacion de profesores

\section{NOTAS}

1 Conforme Brisolla (2003), o Brasil é considerado o quarto mercado do mundo em relação ao crescimento de academias de ginástica.

2 Ainda que haja cursos de Licenciatura e de Bacharelado em Educação Física, que exigem o uso de nomenclaturas diferenciadas, no ponto de vista da autora, a prática do profissional ou do professor de Educação Física reside na intervenção pedagógica.

3 Este trabalho é parte da tese de Doutorado intitulada "Do corpo design à educação sociocorporal: o corpo na formação de professores 
de Educação Física", defendida pela autora na Faculdade de Educação da UFRJ.

4 Para Le Breton (2000), a sociologia do corpo é um capítulo da sociologia ainda em construção. Não se trata de uma disciplina, mas da proliferação de discursos e práticas acerca do corpo, o qual é entendido como fenômeno social e cultural, carregado de símbolos, representações e imaginários.

5 Conforme dito anteriormente, este grupo se refere aos professores que trabalham com disciplinas ligadas ao esporte. Tal expressão será utilizada em outras oportunidades, quando mencionados os professores de outros grupos, como os de Escola, Academia e Corpo.

6 Conforme verificado, há leituras de apoio indicadas aos alunos, com base neste autor.

\section{REFERÊNCIAS}

BRACHT, V. Esporte na escola e esporte de rendimento. Movimento, Porto Alegre, ano 6, n. 12, p. 14- 24, jan. 2000.

BRISOLLA, F. O aquecimento das academias. Veja Rio, Rio de Janeiro, ano 12, n. 13, p. 14-19, abr. 2003.

CAMPELO, C. R. Cal(e)idoscorpos: um estudo semiótico do corpo e seus códigos. São Paulo: Annablume, 1996.

DAOLIO, J. Da cultura do corpo. 4. ed. Campinas, SP: Papirus, 1999.

FERREIRA, A. B. H. Novo dicionário da língua portuguesa. 2. ed. rev. e ampl. Rio de Janeiro: Nova Fronteira, 1999.

FOUCAULT, M. Vigiar e punir: história da violência nas prisões. 23. ed. Petrópolis: Vozes, 2000.

FRANK, A. W. For a sociology of the body: an analytical review. In: FEATHERSTONE, M.; HEPWORTH, M.; TURNER, B. The body: social process and cultural theory. London: Sage, 1999.

GOLDENBERG, M.; RAMOS, M. S. A civilização das formas: o corpo como valor. In: GOLDENBERG, M. (Org.). $N u$ \& vestido: dez antropólogos revelam a cultura do corpo carioca. Rio de Janeiro: Record, 2002. 
LE BRETON, D. La sociologie du corps. 4. éd. Paris: Presses Universitaires de France, 2000. . L'adieu au corps. Paris: Metailié, 1999.

PEREIRA, C. A. M. Cultura do corpo em contexto de alta visibilidade. In: CONGRESSO DE EDUCAÇÃO FÍSICA E DESPORTO DOS PAÍSES DE LÍNGUA PORTUGUESA, 9., 2002, São Luís. Coleção Prata da Casa. Edição Especial.

RESENDE, H. G. Reflexões sobre algumas contradições da Educação Física no âmbito da escola pública e alguns caminhos didático-pedagógicos na perspectiva da cultura corporal. Movimento, Porto Alegre, ano 1, n. 1, p. 21-28, set. 1994.

SOARES, C. L. Fundamentos da Educação Física escolar. Revista Brasileira de Estudos Pedagógicos, Brasília, v. 71 n. 167, p. 51- 68, janfev. 1990.

Recebido: 31/03/2005

Aprovado: 01/06/2005

Endereço para correspondência:

Coordenação de Pós-Graduação

Escola de Educação Física e Desportos da UFRJ Avenida Pau Brasil, 540 - Ilha da Cidade Universitária Rio de Janeiro - RJ

CEP 21949-900

Tel. (21) 2562-6803

E-mail: sagatti@rio.com.br 
